\title{
Relações Públicas e Comunicação Organizacional: das práticas à institucionalização acadêmica
}

\section{Public Relations and Organizational Communication: from practices to academic institutionalization}

\section{Relaciones Públicas y Comunicación Organizacional: de las prácticas a la institucionalización académica}

\section{Margarida Maria Krohling Kunsch}

- Professora titular e pesquisadora da Escola de Comunicações e Artes da Universidade de São Paulo (ECA-USP)

- Livre-docente em Teoria da Comunicação Institucional: Políticas e Processos pela ECA-USP

- Doutora e mestre em Ciências da Comunicação e livre-docência pela ECA-USP

- Presidente da Comissão de Pós-Graduação da ECA-USP

- Presidente da Associação Brasileira de Pesquisadores de Comunicação Organizacional e Relações Públicas (Abrapcorp)

- Diretora de Relações Internacionais da Federação Brasileira das Associações Científicas e Acadêmicas de Comunicação (Socicom)

- Membro do Conselho Consultivo Associação Brasileira de Comunicação Empresarial (Aberje)

- Ex-presidente (1987-1989; 1991-1993) da Sociedade Brasileira de Estudos Interdisciplinares da Comunicação (Intercom)

- Ex-presidente (1998-2002; 2002-2005) da Asociación Latinoamericana de Investigadores de la Comunicación (Alaic)

- Autora de três obras próprias e de grande número de capítulos de livros e artigos em periódicos nacionais e internacionais

- Organizadora de mais de trinta coletâneas científicas de Comunicação

- mkkunsch@usp.br 
Analisam-se os campos das Relações Públicas e da Comunicação Organizacional a partir de suas práticas. Descrevem-se alguns fundamentos conceituais que delimitam possíveis fronteiras e ao mesmo tempo explicitam possibilidades de interfaces das duas áreas. Quais seriam as diferenças e as semelhanças? Como se processam as interfaces? Quais seriam as interconexões entre os estudos e as práticas? São questões levantadas para o debate.

PALAVRAS-CHAVE: COMUNICAÇÃO ORGANIZACIONAL • RELAÇÕES PÚBLICAS • PRÁTICAS • CONCEITOS • INTERFACES • INSTITUCIONALIZAÇÃO • CAMPO ACADÊMICO

Abstract

This study analyzes the fields of Public Relations and Organizational Communication based on their practices. Certain conceptual foundations are described that delimit possible frontiers and at the same time reveal possibilities of interfaces by the two areas. What would the differences and similarities be? How are the interfaces processed? Which would be the interconnections between the studies and the practices? These are the questions that are raised for debate.

KEYWORDS: ORGANIZATIONAL COMMUNICATION • PUBLIC RELATIONS - PRACTICES • CONCEPTS • INTERFACES • INSTITUTIONALIZATION • ACADEMIC FIELD

\section{Resumen}

Se analizan los campos de las Relaciones Públicas y de la Comunicación Organizacional a partir de sus prácticas. Se describen algunos fundamentos conceptuales que delimitan posibles fronteras y, al mismo tiempo, explicitan posibilidades de interfaces de las dos áreas. ¿Cuáles serían las diferencias y las semejanzas? ¿Cómo se procesan las interfaces? ¿Cuáles serían las interconexiones entre los estudios y las prácticas? Son cuestiones propuestas para el debate.

PALABRAS CLAVE: COMUNICACIÓN ORGANIZACIONAL • RELACIONES PÚBLICAS • PRÁCTICAS • CONCEPTOS • INTERFACES • INSTITUCIONALIZACIÓN • CAMPO ACADÉMICO 
$\mathrm{N}$ esta primeira década deste terceiro milênio a Comunicação Organizacional e as Relações Públicas têm merecido destaque, quer no âmbito das Ciências da comunicação, quer nas práticas do mercado profissional. Estima-se que, dada a complexidade vivida pelas instituições e organizações nesta era digital, estas se veem obrigadas a repensar suas formas e estratégias de se comunicar. Com isso não há mais lugar para improvisações. Nesse sentido buscam-se na academia os aportes teóricos como uma aliança necessária para uma base científica do fazer comunicativo cotidiano. Analisar sumariamente a evolução dessas práticas ao longo da história e ao mesmo tempo pincelar alguns aspectos conceituais sobre essas áreas é o propósito central deste artigo.

Evolução das duas áreas

\section{Das aplicações técnicas à visão estratégica}

Como prática profissional mundial, as Relações Públicas existem desde o início do século XX, sobretudo nos Estados Unidos, quando surgiram como forma de ajudar as grandes corporações de negócios e os departamentos de governo a se relacionarem melhor com os seus públicos, a opinião pública e a sociedade. Essas relações estavam abaladas desde o final do século XIX, quando tanto as empresas quanto os governos não levavam em conta os interesses dos públicos e pouco se importavam com a sua falta de credibilidade junto à opinião pública.

No Brasil a prática de Relações Públicas teve início em 30 de janeiro de 1914, por meio da empresa canadense de eletricidade The São Paulo Tramway Light and Power Company Limited, hoje Eletricidade de São Paulo S.A. (Eletropaulo), sob a liderança Eduardo Pinheiro Lobo, patrono da profissão no País. No entanto, apesar de algumas iniciativas isoladas anteriores na esfera governamental, seu desenvolvimento só viria a ocorrer de fato a partir da década de 1950 (KUNSCH,1997).

Ao longo da história, a prática das Relações Públicas passou por grandes transformações. Por muito tempo uma função meramente técnica, ela é hoje entendida como uma função estratégica indispensável para que as organizações se posicionem institucionalmente e administrem com eficácia seus relacionamentos com os públicos estratégicos (KUNSCH, 2003).

A Comunicação Organizacional, na forma em que se acha configurada hoje em dia, é fruto de sementes lançadas no período da Revolução Industrial, que ensejaria grandes e rápidas transformações em todo o mundo. As primeiras manifestações se processaram no formato de ordens e informações, assumindo mais características de uma comunicação administrativa. 
As mudanças provocadas com o processo de industrialização obrigaram as empresas a buscar novas formas de comunicação com o público interno, por meio de publicações dirigidas especialmente aos empregados, e com o público externo, por meio de publicações centradas nos produtos, para fazer frente à concorrência e a um novo processo de comercialização. Assim, a propaganda foi pioneira em buscar formas de comunicação publicitária com o mundo exterior, especialmente com o consumidor.

Com a evolução do seu uso e a importância crescente nos processos de gestão e na divulgação institucional propriamente dita, bem como o desenvolvimento industrial mais acentuado do País a partir dos anos 1950, a comunicação nas organizações foi assumindo novas características, sendo mais produzida tecnicamente e baseando-se em pesquisas de opinião entre os diferentes públicos, até chegar ao estágio em que se encontra hoje em muitas organizações top modernas, nas quais atinge um grau de sofisticação na sua elaboração e, também, um caráter estratégico no conjunto dos objetivos institucionais e corporativos. Em outras palavras, da comunicação funcional e administrativa passa-se à comunicação estratégica; do Jornalismo Empresarial, à Comunicação Empresarial; e da Comunicação Empresarial à Comunicação Organizacional em uma perspectiva mais abrangente e mais complexa.

\section{Institucionalização dos estudos}

Os estudos de Comunicação Organizacional e de Relações Públicas, no início deste terceiro milênio, têm adquirido um status de institucionalização acadêmica no panorama mundial. Essas áreas deixam de voltar-se simplesmente para as práticas profissionais e organizacionais, sendo consideradas e tratadas também como áreas acadêmicas.

Quanto às Relações Públicas, mais estudiosos internacionais compartilham essa percepção. Friz Cropp e J. David Pincus (2001 p. 189-203), ao descreverem a evolução das práticas da área, destacam as várias perspectivas de sua abordagem no âmbito acadêmico e profissional. Para James Grunig (2003, p. 69), "as Relações Públicas estão se tornando uma profissão fundamentada em conhecimentos acadêmicos". Portanto, podemos afirmar que hoje não se pode mais ver as Relações Públicas apenas como atividade ou prática profissional, constituindo elas, também, um campo de conhecimento específico. No Brasil a área está institucionalizada nessas duas vertentes.

Como áreas de conhecimento, Comunicação Organizacional e Relações Públicas inserem-se no âmbito das Ciências da Comunicação e das Ciências Sociais Aplicadas. Possuem um corpus de conhecimento com literatura específica, teorias reconhecidas mundialmente, cursos de pós-graduação (lato sensu e stricto sensu), pesquisas científicas etc. Constituem, portanto, campos acadêmicos e aplicados de múltiplas perspectivas. 
Sua identidade e sua matriz acadêmica têm se pautado hegemonicamente pelo pensamento comunicacional norte-americano. Conforme registra a história, tanto as práticas como os estudos surgiram e tiveram sua evolução inicial nos Estados Unidos. Mas hoje pesquisadores de todos os continentes já contemplam, de forma cada vez mais consistente, essas duas áreas, principalmente a Comunicação Organizacional. Grandes avanços epistemológicos foram alcançados até agora - dos estudos de canais, mensagens, fluxos, redes, audiências etc. entre os anos 1950 e 1970, passando pelos estudos interpretativos a partir de 1980, até a multiplicidade de enfoques na primeira década de 2000.

Esses campos do saber têm como característica geral a sistematização reflexiva das práticas profissionais e da práxis da comunicação nas e das organizações. Por serem áreas altamente aplicadas, é fundamental que os estudos levem em conta a natureza das organizações no contexto da dinâmica da história e das conjunturas sociais, políticas e econômicas para prefigurar os fenômenos e objetos de investigação científica.

\section{Delimitações conceituais}

Uma questão central que precisa ser mais bem fundamentada diz respeito aos conceitos que, ao mesmo tempo, diferenciam os campos da Comunicação Organizacional e das Relações Públicas e, por outro, expressam suas interfaces e interconexões. Uma obervação que merece ser registrada é que, com o livro Crystallizing public opinion, de Edward Bernays (1923), os estudos acadêmicos específicos de Relações Públicas tiveram início antes dos de Comunicação Organizacional, os quais se sistematizariam só a partir da década de 1950. Em sua obra Bernays abordava, na primeira parte, o escopo, as funções, a definição, a necessidade e papel das Relações Públicas na sociedade; na segunda, a atuação da área; na terceira, os diferentes métodos de comunicação e persuasão que impactam os públicos; e na quarta, o papel do assessor de relações públicas , "destinado a criar uma consciência pública e servir com a máxima utilidade à sociedade na qual vive". No curto espaço deste texto não daria para desenvolver essas bases conceituais da forma como gostaríamos. Apenas com o intuito de contribuir com o debate, destacaremos algumas percepções que temos a respeito da temática ${ }^{1}$.

1 Nos congressos anuais da Associação Brasileira de Pesquisadores de Comunicação Organizacional e de Relações Públicas (Abrapcorp) instituímos um fórum para debater as bases conceituais desses dois campos. Há um grupo de pesquisadores brasileiros desenvolvendo um estudo sobre essa temática, cujo primeiro resultado é a publicação do dossiê desta edição da Organicom. 


\section{Comunicação Organizacional}

A Comunicação Organizacional precisa ser entendida de forma ampla e abrangente. Pode-se dizer que é uma disciplina que estuda como se processa o fenômeno comunicacional dentro das organizações e todo o seu contexto político, econômico e social. Como fenômeno inerente à natureza das organizações e aos agrupamentos de pessoas que a integram, a Comunicação Organizacional envolve os processos comunicativos e todos os seus elementos constitutivos. Nesse contexto faz-se necessário ver a comunicação inserida nos processos simbólicos e com foco nos significados dos agentes envolvidos, dos relacionamentos interpessoais e grupais, valorizando as práticas comunicativas cotidianas e as interações nas suas mais diversas formas de manifestação e construção social.

Outra vertente a considerar é como se configuram as diferentes modalidades que permeiam a concepção e as práticas da Comunicação Organizacional, dentro de uma visão que denominamos "comunicação organizacional integrada", que, compreendendo a Comunicação Institucional, a Comunicação Mercadológica, a Comunicação Interna e a Comunicação Administrativa (KUNSCH, 2003, p. 149), acontece a partir de objetivos e propósitos específicos.

\section{Relações Públicas}

Entendemos as Relações Públicas como parte integrante do subsistema institucional das organizações, cabendo-lhe o papel fundamental de cuidar dos relacionamentos públicos dos agrupamentos sociais que podem ser configurados a partir de diferentes tipologias e características estruturais, envolvendo das organizações públicas às empresas privadas e aos segmentos organizados da sociedade civil. Tal incumbência implica uma série de questões que envolvem planejamento, gestão, processos, técnicas, instrumentos, desempenho de funções e atividades com bases científicas e suporte técnico e tecnológico.

As Relações públicas, como campo acadêmico e atividade profissional, têm como objetos as organizações e seus públicos, instâncias distintas mas que se relacionam dialeticamente. É com elas que a área trabalha, promovendo e administrando relacionamentos e, muitas vezes, mediando conflitos, valendo-se para tanto de estratégias e de programas de comunicação de acordo com diferentes situações reais do ambiente social. Philip Lesly (1995), ao descrever a natureza e o papel das Relações Públicas, mostra bem a amplitude do universo de públicos com os quais as organizações podem se relacionar.

Em síntese, as Relações Públicas, como área aplicada, se envolvem com o planejamento e a gestão da comunicação nas e das organizações. Avaliam os comportamentos institucionais e dos públicos, por meio de pesquisas de opinião pública e auditorias sociais e de imagem. Administram percepções e relaciona- 
mentos públicos. Para tanto exercem, basicamente, quatro funções - administrativa, estratégica, mediadora e política (KUNSCH, 2003, p.100-117) - e desenvolvem inúmeras atividades, por meio de técnicas e instrumentos específicos.

Com base nos conceitos apresentados, podemos deduzir que há diferenças de propósitos e dimensões entre essas áreas, apesar das proximidades, interconexões e interfaces no conjunto dos objetos de estudo. A Comunicação Organizacional deve ser entendida, sobretudo, como um fenômeno que ocorre nas organizações com toda uma complexidade de processos. As Relações Públicas lidam com a gestão desses processos utilizando todo o aparato da comunicação para fazer as mediações com os públicos.

\section{Interfaces e convergência}

No Brasil, estudos já realizados (KUNSCH, 2009a, 2009b) identificam que se fazem muito presentes as interfaces entre os dois campos, tanto no âmbito acadêmico como na prática. Trata-se de uma característica singular da realidade brasileira, diferentemente, por exemplo, do que ocorre nos Estados Unidos. Constituímos uma comunidade acadêmica representativa de Comunicação Organizacional $e$ Relações Públicas, sendo o diálogo entre esses dois campos uma realidade construtiva e a caminho da efetiva consolidação.

Acreditamos que ambas as áreas possuem suas bases conceituais próprias, suas especificidades e propósitos diferentes, mas se interconectam na medida em que põem o foco em organizações, pessoas e grupos, bem como na formação de comportamentos públicos. A Comunicação Organizacional, como fenômeno intrínseco à natureza das organizações, é uma realidade dinâmica, à semelhança de um organismo vivo. A área de Relações Públicas, ao trabalhar diretamente com organizações, públicos, imagem, reputação e comportamentos coletivos, tangencia e interpenetra a Comunicação Organizacional. Assim, as interfaces das duas áreas são mais do que evidentes. Para compreender e aplicar os fundamentos teóricos das Relações Públicas, é necessário também conhecer o espectro abrangente da Comunicação Organizacional e de áreas afins. Todo esse processo mediador só é possível acontecer com e por meio da comunicação revestida de uma abrangência e complexidade sem precedentes.

\section{Referências}

BERNAYS, Edward L. Crystallizing public opinion. New York: Liveright Publishing Corporation, 1923.

CROPP, Fritz; PINCUS, David. The mystery of public relations: unraveling its past. In: HEAT, Robert. Handbook of public relations. Thousand Oaks / London: Sage, 2001. p. 189-203.

GRUNIG, James E. A função das relações públicas na administração e sua contribuição para a efetividade organizacional e societal. Trad. de John Franklin Arce. Comunicação \& Sociedade, São Bernardo do Campo, PósCom-Metodista, a. 24, n. 39, p. 67-92, 1. sem. 2003. 
KUNSCH, Margarida M. Krohling (Org.). Relações públicas: história, teorias e estratégias nas organizações contemporâneas. São Paulo: Saraiva, 2009a. 512 p.

(Org.). Comunicação organizacional. Vol. 1. Histórico, fundamentos e processos. São Paulo: Saraiva, 2009b. 408 p.

Planejamento de relações públicas na comunicação integrada. [1986]. 4. ed. rev., atual. e ampl. São Paulo: Summus, 2003a.

(Org.). Relações públicas e modernidade: novos paradigmas na Comunicação Organizacional. São Paulo: Summus, 1997. LESLY, Philip. Os fundamentos de relações públicas e da comunicação. São Paulo: Pioneira, 1995.

56 RELAÇõES PÚBLICAS E COMUNICAÇÃo ORGANIZACIONAL: DAS PRÁTICAS À INSTITUCIONALIZAÇÃO ACADÊMICA • MARGARIDA M. KROHLING KUNSCH 